\title{
Research on the Optimum Shape and Size of Potato Ridges - Partial Results from Trial Year 2013
}

\author{
Iván Zoltán VITOS ${ }^{1 *}$, Gavrilă MORAR ${ }^{1}$, Luiza MIKE², Cristina MOLDOVAN ${ }^{1}$ \\ ${ }^{1}$ Faculty of Agriculture, University of Agricultural Sciences and Veterinary Medicine Cluj-Napoca \\ ${ }^{2}$ Potato Research and Development Station Tg. Secuiesc \\ * corresponding author: vitosivan@yahoo.com
}

Bulletin USAMV series Agriculture 71(2)/2014

Print ISSN 1843-5246; Electronic ISSN 1843-5386

DOI 10.15835/buasvmcn-agr: 10608

\begin{abstract}
The partial results from the research carried out in 2013 at the Potato Research and Development Station Tîrgu Secuiesc on the size and shape of the ridges and the influence of planting density in the case of two varieties and two types of ridges (ridges in one row and two rows) are presented. The pedoclimatic conditions characteristic of this trial year were favorable for potato cultivation. In the study of the optimal shape of potato ridges three different shapes have been studied: triangular shape, trapezoidal shape and double-trapezoidal shape. In the study of the optimal size of potato ridges three different ridge sizes were made: with cross-sectional areas of 800 $\mathrm{cm}^{2}, 1200 \mathrm{~cm}^{2}$ and $1600 \mathrm{~cm}^{2}$. The biological material used in these two experiments was the Bella Rosa variety, which is part of the class A biological category. The research on the influence of planting density was conducted on two potato varieties planted in ridges in a single row and in two rows: one that forms many but small tubers, the class A Gared variety and the second one that forms fewer but larger tubers, the class A Bella Rosa variety. Experiments with three different planting densities for each type of variety and each type of ridge (ridges in one row and two rows) were carried out: 40.000 plants/ha, 60.000 plants/ha and 80.000 plants/ha. For all variants four rows were planted and the process was repeated four times. The common technology of ridge ploughing was used and mechanically performed phytosanitary treatments were executed with the usual products. To achieve the objectives the following elements were taken into consideration: yield and production (kg/ha), - average weight of a tuber (g), average number of tubers per nest, average number and weight of tubers under and over 40 $\mathrm{mm}$ per nest.An analysis of variance was carried out for completely randomized plots and the data processing was accomplished by using average values, the "t-test" at 5\%, 1\%, 0,1\% significant difference levels and the Duncan Multiple Range Test.
\end{abstract}

Keywords: density, potato, ridge, size, shape.

\section{INTRODUCTION}

In terms of climate conditions the trial year of 2013 in the basin of Kézdivásárhely, Covasna county can be considered a normal agricultural year during which all meteorological parameters were close to the long-term average values.

The obtained results in 2013 differed from trial to trial when compared to the results of the previous year of study (2012), considered a drought year due to the low value of total rainfall which was below the long-term average and during which the growing season produced a value of $115.4 \mathrm{~mm}$ rainfall.
This allows us to have a broader vision on the optimal ridge shape and ridge size, on the behavior of different potato varieties while applying different planting densities in several different types of ridges, in varied pedoclimatic conditions, sometimes in even extreme ones.

Compared to the previous trial year, in 2013 in addition to tuber yield, number of tubers per nest and average tuber weight we also traced the number of tubers that were bigger and smaller than $40 \mathrm{~mm}$ in the field trials meant to study the influence of planting density for two different varieties in ridges in a single row and in two rows. 


\section{MATERIALS AND METHODS}

For studying the suitable ridge shapes and sizes we proposed the following objectives:

- the study of shape: - the optimal shape (triangular, trapezoidal, double-trapezoidal) which ensures thorough coverage of seedbeds and highest yield;

- the study of size:

- the optimal ridge height achieved by the usage of different machinery to ensure the highest yield;

- the lowest number of potato-sized or larger lumps of soil;

- correlation between the dimensions of the nest and the shape and size of the ridge (fewer and larger tubers and many smaller ones);

- the study of planting density depending on the shape and size of the ridges, within the range of $40.000,60.000$ to 80.000 plants / ha.

- number of tubers per nest that are bigger and smaller than $40 \mathrm{~mm}$ trials:

For our objectives we proposed the following

Trial 1. The optimum ridge shape

3 different shapes for ridges of the same size $\left(1200 \mathrm{~cm}^{2}\right)$, one cultivar (Bella Rosa):

- a1 - triangular shape;

- a2 - trapezoidal in one row;

- a3 - trapezoidal in 2 rows;

For this experiment the Bella Rosa variety was used in this year as well and the planting took place on the fields for experimental planting belonging to the Potato Research and Development Station in Tg. Secuiesc, Covasna county. The triangular shaped ridges were made by a ridging plough before applying herbicides, the trapezoidal ones were shaped with a single row cultivator and the double-trapezoidal ones were shaped with a tworow cultivator.

Trial 2. The optimum ridge size

3 different sizes for ridges having the same shape (simple trapezoidal), one cultivar (Bella Rosa):

- b1 - cross-sectional area of $800 \mathrm{~cm}^{2}$

- b2 - cross-sectional area of $1200 \mathrm{~cm}^{2}$

- b3 - cross-sectional area of $1600 \mathrm{~cm}^{2}$
Ridging was executed with rotary ridgers and cultivators.

Trial 3. The influence of planting density on two potato varieties planted in ridges in a single row and in two rows

In this trial two varieties of potatoes have been used (a variety with fewer but larger tubers - Bella Rosa and another that has a lot of small tubers Gared) with three different planting densities - 40.000 seed tubers / ha, 60.000 seed tubers / ha, 80.000 seed tubers / ha and with two types of ridges, in a single row and in a double row (simple and double trapezoidal shape).

In 2013 the manual planting process was executed on May 20 and the harvest was conducted on September 16.

\section{RESULTS AND DISCUSSION}

In 2013 the recorded temperature values in the basin of Târgu Secuiesc were close to the long-term average values thus favoring potato cultivation. Each month throughout the growing season produced a higher average temperature value when compared to the long-term average, with the exception of September. However, these differences were not significant.

The mean annual amount of precipitation was $42,8 \mathrm{~mm}$ higher than the long-term average and the Meteorological Station of Târgu Secuiesc measured a 460,7 $\mathrm{mm}$ rainfall amount throughout the growing season. Despite the surplus of 73,2 $\mathrm{mm}$ of water in comparison to the long-term average during the growing season the crop was not affected due to the drought conditions of the previous year.

Soil factors can also limit plant growth because the crop reacts strongly to all soil features and properties. The fields in the area of $\mathrm{Tg}$. Secuiesc have varied soil textures: silty-clay, clay, sandy clay, they are deep, with groundwater levels of 1.0-1.5 $\mathrm{m}$, ensuring favorable conditions for mechanized potato production.

Dominant soil classes within the area of S.C.D.C. Tg. Secuiesc are phaeozems, which occur in cooler environmental conditions and are sometimes wetter than "ordinary" chernozems. Those formed on medium clay have excellent air and water conditions thus being the most suitable 
soil group of the area and the most favorable for potato production.

\section{Trial results in relation to the optimum shape of ridges in 2013}

Potato tuber yield (kg/ ha)

In accordance with the Duncan test and the difference limit there was no significant divergence in the yield of tubers planted in trapezoidal and double-trapezoidal shaped ridges of the same size from the yield of the ones planted in triangular shaped ridges, considered to be the control variants in 2013. As a result we can state that similarly to the previous trial year the shape of ridges did not influence tuber production. (table 1)
Analyzing the number of tubers per nest obtained from the three differently shaped ridges using the t-test and Duncan's test show that fewer potato tubers were harvested from planting holes in trapezoidal shaped ridges and more were obtained from nests in double-trapezoidal ridges in comparison with the triangular shaped ones, considered to be the control variants. However, the differences are not confirmed statistically. (table 2).

Regarding the average tuber weight, potatoes harvested from trapezoidal and double-trapezoidal shaped ridges showed considerably higher values than the ones harvested from triangular shaped ridges. According to the statistical calculation there were significantly positive differences regar-

Tab. 1. The influence of ridge shape on potato tuber yield

\begin{tabular}{cccccc}
\hline Shape of the ridge & $\mathrm{kg} / \mathrm{ha}$ & $\%$ & Difference $(\mathrm{kg})$ & Significance & Duncan's test \\
\hline Triangular & 28047,55 & 100.0 & 0 & Mt. & $\mathrm{A}$ \\
\hline Trapezoidal & 28273,73 & 100.8 & 226,18 & - & $\mathrm{A}$ \\
\hline Double trapezoidal & 32404,73 & 115.5 & 4357,18 & \pm & $\mathrm{A}$ \\
\hline DL (p 5\%) & & 4359,88 & & & \\
DL (p 1\%) & 6602,10 & & & \\
DL (p 0,1\%) & & 10606,07 & & & \\
DS (teor.) & & 4353,81 & & & \\
DS (teor.) & & 4517,39 & &
\end{tabular}

Tab. 2. The influence of ridge shape on the number of tubers under the hill

\begin{tabular}{lccccc}
\hline Shape of the ridge & no./ hill & $\%$ & Difference (no.) & Significance & Duncan's test \\
\hline Triangular & 3,48 & 100 & 0 & Mt. & A \\
\hline Trapezoidal & 3,09 & 88,9 & $-0,39$ & - & A \\
\hline Double trapezoidal & 3,53 & 101,5 & 0,05 & - & \\
\hline DL (p 5\%) & \multicolumn{5}{c}{0,56} \\
DL (p 1\%) & 0,85 & & \\
DL (p 0,1\%) & \multicolumn{7}{c}{0,37} & & \\
DS (teor.) & 0,56 & & \\
DS (teor.) & & 0,58 & &
\end{tabular}

Tab. 3. The influence of ridge shape on the average weight of a tuber

\begin{tabular}{cccccc}
\hline Shape of the ridge & Average weight $(\mathrm{g})$ & $\%$ & Difference $(\mathrm{g})$ & Significance & Duncan's test \\
\hline Triangular & 143,75 & 100 & 0 & Mt. & A \\
\hline Trapezoidal & 165,50 & 115,1 & 21,75 & $*$ & B \\
\hline Double trapezoidal & 164,50 & 114,4 & 20,75 & $*$ & \\
\hline DL (p 5\%) & & 20,34 & & & \\
DL (p 1\%) & 30,80 & & & \\
DL (p 0,1\%) & & 49,48 & & & \\
DS (teor.) & & 20,31 & & & \\
DS (teor.) & & 21,08 & & &
\end{tabular}


ding the weight of tubers harvested from trapezoidal and double trapezoidal shaped ridges in comparison with the ones harvested from triangular shaped ridges, considered to be the control variants. Due to the statistical analysis of the Duncan test results we could establish a noticeable oscillation between the values of average tuber weight among the three different shapes of ridges. (Table 3). These results confirm the findings of the previous trial year (2012) when the same results had been discovered: the average tuber weight in trapezoidal shaped ridges was bigger when compared to the value produced by triangular shaped ridges.

\section{Trial results regarding the optimal size of ridges}

The field trials that involved experimenting with different sizes of ridges of the same shape proved that compared to the control variant (the yield of tubers in ridges with the cross-sectional area of $800 \mathrm{~cm}^{2}$ ) there was a significant decrease in yield regarding ridges with the cross-sectional area of $1200 \mathrm{~cm}^{2}$ whereas regarding ridges with the cross-sectional area of $1600 \mathrm{~cm} 2$ there was also a decrease in yield, though statistically insignificant. (table 4)

Tab. 4. The influence of ridge size on tuber yield
Ridges with the cross-sectional area of 1200 $\mathrm{cm}^{2}$ and $1600 \mathrm{~cm}^{2}$ produced a significantly lower number of tubers per nest when compared to the control variant $\left(800 \mathrm{~cm}^{2}\right)$ and ridges with the cross-sectional area of $1200 \mathrm{~cm}^{2}$ showed the lowest number of tubers per planting hole. Comparing the average number of tubers per plant with the help of the Duncan test we can observe significant differences between the values calculated for the two different ridge sizes in comparison with the control variant. (Table 5).

In 2013 the average weight of single tuber found in ridges with the cross-sectional area of $1600 \mathrm{~cm}^{2}$ was higher than the average weight of single tuber produced in ridges with the crosssectional areas of $1200 \mathrm{~cm}^{2}$ and $800 \mathrm{~cm}^{2}$ (control variant), but the discrepancy between values was statistically insignificant, fact also confirmed by the Duncan test (table 6).

Trial results regarding the influence of planting density on two varieties of potatoes planted in ridges in a single row and a double row

After analyzing the influence of the different cultivars on the yield of tubers we noticed a higher yield in the case of the Bella Rosa variety (characterized by fewer but large tubers) in comparison with the Gared variety, considered the control variant (cultivar with more but smaller

\begin{tabular}{cccccc}
\hline Size of the ridge & $\mathrm{Kg} / \mathrm{ha}$ & $\%$ & Diff. $(\mathrm{kg})$ & Significance & Duncan's test \\
\hline $800 \mathrm{~cm}^{2}$ & 36166,63 & 100 & 0 & Mt. & $\mathrm{B}$ \\
\hline $1200 \mathrm{~cm}^{2}$ & 30904,70 & 85,5 & $-5261,93$ & 0 & $\mathrm{~A}$ \\
\hline $1600 \mathrm{~cm}^{2}$ & 33404,70 & 92,4 & $-2761,92$ & - & \\
\hline DL (p 5\%) & & 3596,33 & & & \\
DL (p 1\%) & 5445,87 & & & \\
DL (p 0,1\%) & & 8748,61 & & & \\
DS (teor.) & & 3591,32 & & & \\
DS (teor.) & & 3726,25 & &
\end{tabular}

Tab. 5. The influence of ridge size on the number of tubers under the hill

\begin{tabular}{cccccc}
\hline Size of the ridge & no./ hill & $\%$ & Difference (nr.) & Significance & Duncan's test \\
\hline $800 \mathrm{~cm}^{2}$ & 4,14 & 100,0 & 0 & Mt. & B \\
\hline $1200 \mathrm{~cm}^{2}$ & 3,52 & 84,9 & $-0,63$ & 0 & A \\
\hline $1600 \mathrm{~cm}^{2}$ & 3,63 & 87,6 & $-0,51$ & 0 & \\
\hline DL (p 5\%) & & 0,48 & & & \\
DL (p 1\%) & & 0,73 & & & \\
DL (p 0,1\%) & & 1,17 & & & \\
DS (teor.) & & 0,48 & & & \\
DS (teor.) & & 0,50 & & &
\end{tabular}


Tab. 6. The influence of ridge size on the average weight of a tuber

\begin{tabular}{lccccc}
\hline Size of the ridge & $\begin{array}{c}\text { Average } \\
\text { weight }(\mathrm{g})\end{array}$ & $\%$ & Difference $(\mathrm{g})$ & Significance & Duncan's Test \\
\hline \multicolumn{1}{c}{$800 \mathrm{~cm}^{2}$} & 157,25 & 100,0 & 0 & Mt. & A \\
\hline $1200 \mathrm{~cm}^{2}$ & 158,00 & 100,5 & 0,75 & - & A \\
\hline $1600 \mathrm{~cm}^{2}$ & 165,50 & 105,2 & 8,25 & - & \\
\hline DL (p 5\%) & & 12,16 & & \\
DL (p 1\%) & 18,41 & & \\
DL (p 0,1\%) & 29,58 & & \\
DS (teor.) & 12,14 & & \\
DS (teor.) & & 12,60 & &
\end{tabular}

Tab.7. The influence of the cultivar on the yield of tubers

\begin{tabular}{cccccc}
\hline Variety & Yield (kg/ ha) & $\%$ & Difference $(\mathrm{kg})$ & Significance & Duncan's test \\
\hline Gared & 23493,99 & 100 & 0 & Mt. & A \\
\hline Bella Rosa & 27021,78 & 115 & 3527,79 & $* *$ & \\
\hline DL (p 5\%) & & 1285,60 & & & \\
DL (p 1\%) & 2360,97 & & & \\
DL (p 0,1\%) & & 5231,33 & &
\end{tabular}

Tab. 8. The influence of planting density on tuber production

\begin{tabular}{cccccc}
\hline Density (plants/ ha) & Yield (kg/ ha) & $\%$ & Difference $(\mathrm{kg})$ & Significance & Duncan's test \\
\hline 40000 & 25080,31 & 100 & 0 & Mt. & A \\
\hline 60000 & 25619,01 & 102,1 & 538,71 & - & A \\
\hline 80000 & 25074,34 & 100 & $-5,96$ & - & \\
\hline DL (p 5\%) & & 1415,97 & & & \\
DL (p 1\%) & 1987,55 & & & \\
DL (p 0,1\%) & & 2805,96 & & & \\
DS (teor.) & & 1414,60 & & & \\
DS (teor.) & & 1483,49 & &
\end{tabular}

Tab. 9. The influence of ridge shape on tuber production

\begin{tabular}{cccccc}
\hline Shape of the ridge & Production $(\mathrm{kg} / \mathrm{ha})$ & $\%$ & Difference $(\mathrm{kg})$ & Significance & Duncan's test \\
\hline Trapezoidal & 24111,06 & 100 & 0 & Mt. & A \\
\hline Double & 26404,71 & 109,5 & 2293,65 & $* *$ & $\mathrm{~B}$ \\
trapezoidal & & 1263,85 & & & \\
\hline DL (p 5\%) & 1733,28 & & \\
DL (p 1\%) & & 2359,18 & & \\
DL (p 0,1\%) & & 1263,91 & &
\end{tabular}

tubers), the difference being a significant one, a fact also proven by the results of the Duncan test. (table 7)

Considering the different cultivars and ridge shapes on average, similar to previous year, the highest yield in 2013 was obtained in the case of 60.000 plants/ha planting density in comparison with the control variant (40.000 plants/ha), while the planting density of 80.000 plants/ha produced a lower yield when compared to the same control variant. Nevertheless, the differences are insignificant. When we compared yields by applying the Duncan test we noticed an insignificant difference in production ( $\mathrm{kg} / \mathrm{ha}$ ). (table 8) 
After analyzing the influence of ridge shapes on tuber yield using the t-test and considering the different cultivars and planting densities on average, significant differences could be confirmed as the double trapezoidal shaped ridges produced higher yield. What is more, applying the Duncan test has also confirmed these results. (Table 9)

Considering the interaction between the shapes of the ridges and the three types of planting densities we discovered a lower yield while harvesting from double trapezoidal shaped ridges at a density of 40.000 plants per hectare though the results were not confirmed statistically. At a density of 60.000 plants / hectare the double trapezoidal shaped ridges produced a higher yield in comparison with the simple trapezoidal shaped ones (control variant), the difference being a significant one. At a density of 80.000 plants per hectare a considerably higher yield of crop was noticed in double trapezoidal shaped ridges than in simple trapezoidal shaped ones. (Table 10)

After the analysis of the interaction between variety, planting density and ridge shape we noticed that the Gared variety produced similar yield values in double trapezoidal shaped ridges at densities of 40000 plants per hectare and 60000 plants per hectare with insignificant differences when compared to the yields of the simple trapezoidal ridges. However at the density of 80000 plants per hectare, the Gared variety produced a significantly higher yield in double trapezoidal shaped ridges.

The Bella Rosa variety produced a lower yield in double trapezoidal shaped ridges at a density of 40000 plants per hectare, but the difference is not statistically significant. With the Bella Rosa variety statistically significant difference occurred at the planting density of 60000 plants per hectare. According to the t-test in this case the double trapezoidal ridges produced higher yield than the simple ones. (Table 11).

What is more, at the planting density of 80000 plants per hectare a highly significant difference in yield was confirmed also by the Duncan test due to the much higher yield that was produced in double trapezoidal ridges when compared to the yield of the simple ones. (Table 11).

Considering the interaction between variety, ridge shapes and planting densities a significant difference in number of tubers under $40 \mathrm{~mm}$ were discovered in the case of the Bella Rosa variety at the densities of 60000 plants per hectare and 80000 plants per hectare, in case of which the double trapezoidal ridges produced a significantly higher number of small tubers than the simple ones, a fact also confirmed by the Duncan test (Table 12).

After studying the Gared variety at all three planting densities, and the Bella Rosa variety at the density of 40000 plants per hectare we

Tab. 10. The influence of planting density and ridge shape interaction upon tuber yield

\begin{tabular}{|c|c|c|c|c|c|c|}
\hline $\begin{array}{c}\text { Density } \\
\text { (plant/ha) }\end{array}$ & $\begin{array}{l}\text { Shape of the } \\
\text { ridge }\end{array}$ & $\begin{array}{c}\text { Yield } \\
\text { (Kg/ ha) }\end{array}$ & $\%$ & Difference (kg) & Significance & Duncan's test \\
\hline \multirow{2}{*}{40000} & $\begin{array}{c}\text { Simple } \\
\text { trapezoidal }\end{array}$ & 25291,63 & 100 & 0 & Mt. & BCD \\
\hline & $\begin{array}{c}\text { Double } \\
\text { trapezoidal }\end{array}$ & 24868,99 & 98,3 & - 422,64 & - & $\mathrm{ABC}$ \\
\hline \multirow{2}{*}{60000} & $\begin{array}{c}\text { Simple } \\
\text { trapezoidal }\end{array}$ & 24380,91 & 100 & 0 & Mt. & $\mathrm{AB}$ \\
\hline & $\begin{array}{c}\text { Double } \\
\text { trapezoidal }\end{array}$ & 26857,11 & 110,2 & 2476,20 & $*$ & $\mathrm{CD}$ \\
\hline \multirow{2}{*}{80000} & $\begin{array}{c}\text { Simple } \\
\text { trapezodial }\end{array}$ & 22660,65 & 100 & 0 & Mt. & A \\
\hline & $\begin{array}{c}\text { Double } \\
\text { trapezoidal }\end{array}$ & 27488,04 & 121,3 & 4827,39 & $* * *$ & D \\
\hline DL (p 5\%) & & & 2189,05 & & & \\
\hline DL (p 1\%) & & & 3002,12 & & & \\
\hline DL (p 0,1\%) & & & 4086,22 & & & \\
\hline
\end{tabular}


Tab. 11. Influence of planting density, variety and ridge shape interaction upon tuber yield

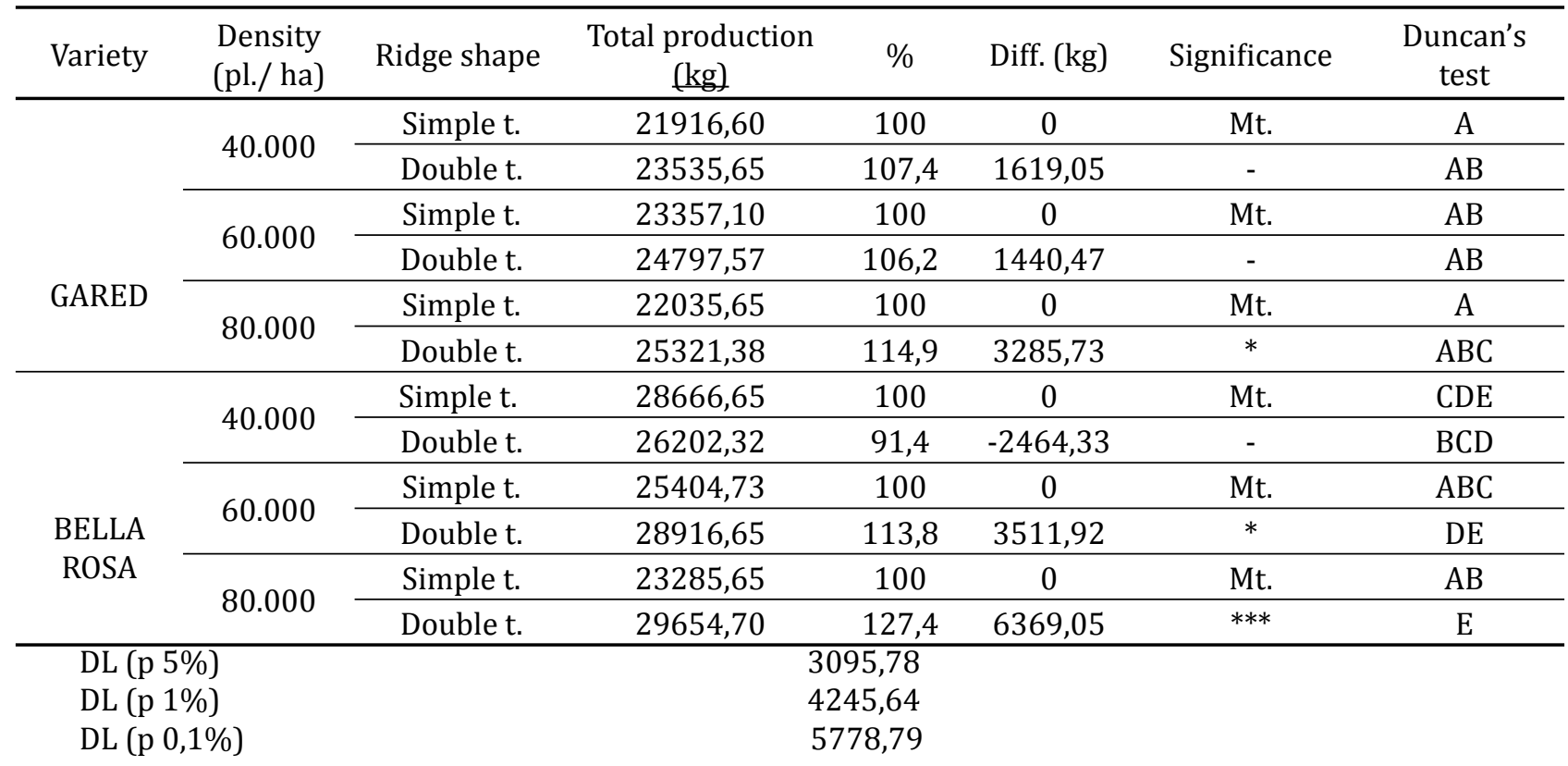

Tab. 12. Influence of planting density, variety and ridge shape interaction upon the number of tubers under $40 \mathrm{~mm}$ per nest

\begin{tabular}{|c|c|c|c|c|c|c|c|}
\hline Variety & $\begin{array}{l}\text { Density } \\
\text { (pl./ ha) }\end{array}$ & Ridge Shape & $\begin{array}{c}\text { Number of } \\
\text { small tubers/ } \\
\text { nest }\end{array}$ & $\%$ & Diff. & Significance & $\begin{array}{c}\text { Duncan's } \\
\text { Test }\end{array}$ \\
\hline \multirow{6}{*}{ GARED } & \multirow{2}{*}{40.000} & Simple t. & 3,43 & 100,0 & 0 & Mt. & $\mathrm{F}$ \\
\hline & & Double t. & 2,93 & 85,4 & $-0,50$ & - & DEF \\
\hline & \multirow{2}{*}{60.000} & Simple t. & 2,73 & 100 & 0 & Mt. & $\mathrm{DE}$ \\
\hline & & Double t. & 2,38 & 87,2 & $-0,35$ & - & $\mathrm{D}$ \\
\hline & \multirow{2}{*}{80.000} & Simple t. & 3,32 & 100 & 0,00 & Mt. & $\mathrm{F}$ \\
\hline & & Double t. & 3,14 & 94,4 & $-0,18$ & - & $\mathrm{EF}$ \\
\hline \multirow{6}{*}{$\begin{array}{l}\text { BELLA } \\
\text { ROSA }\end{array}$} & \multirow{2}{*}{40.000} & Simple t. & 1,25 & 100 & 0 & Mt. & $\mathrm{BC}$ \\
\hline & & Double t. & 1,09 & 87,2 & $-0,16$ & - & $B$ \\
\hline & \multirow{2}{*}{60.000} & Simple t. & 1,20 & 100 & 0 & Mt. & $\mathrm{BC}$ \\
\hline & & Double $t$. & 1,75 & 145,4 & 0,55 & $*$ & $\mathrm{C}$ \\
\hline & \multirow{2}{*}{80.000} & Simple t. & 0,37 & 100 & 0 & Mt. & $\mathrm{A}$ \\
\hline & & Double $t$. & 1,09 & 293,3 & 0,72 & $*$ & $\mathrm{~B}$ \\
\hline \multicolumn{2}{|c|}{ DL (p 5\%) } & & 0,53 & & & & \\
\hline \multirow{2}{*}{\multicolumn{2}{|c|}{ DL (p 1\%) }} & & 0,73 & & & & \\
\hline & & & 0,99 & & & & \\
\hline
\end{tabular}

could observe that the double trapezoidal ridges produced a lower number of tubers under 40 $\mathrm{mm}$ in contrast with the simple trapezoidal ridges. However, these differences are statistically insignificant.

Taking into consideration the interaction between variety, ridge shape and planting density on the number of tubers over $40 \mathrm{~mm}$ significant difference occurred in the case of the Gared variety planted at a density of 40000 plants per hectare in double trapezoidal shaped ridges, where a significantly higher number of large tubers was discovered in contrast to the simple trapezoidal shaped ones (table 13). 
Tab. 13. Influence of planting density, variety and ridge shape interaction upon the number of tubers over $40 \mathrm{~mm}$ per nest

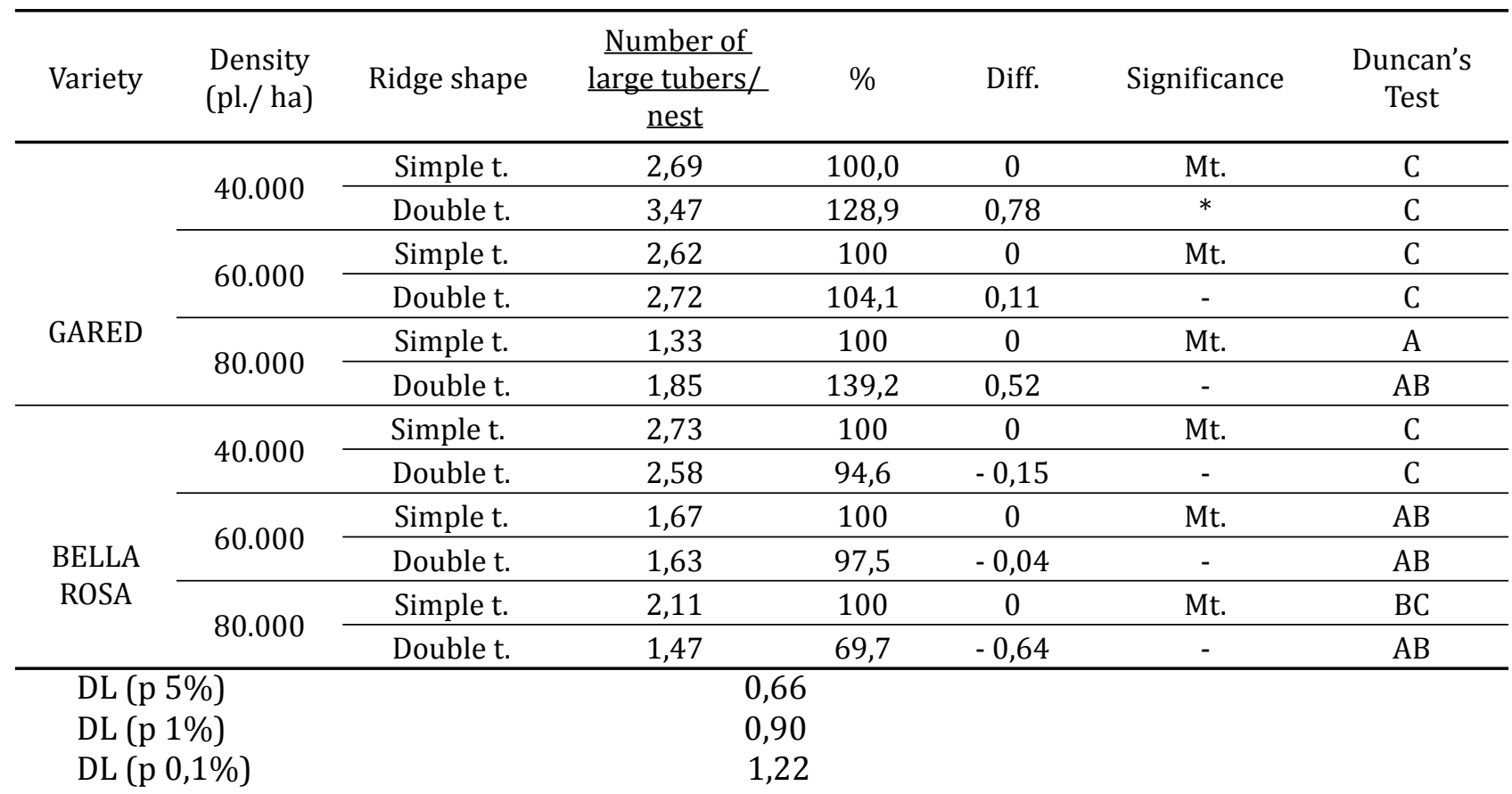

Tab. 14. Influence of planting density, variety and ridge shape interaction upon the total number of tubers per plant

\begin{tabular}{|c|c|c|c|c|c|c|c|}
\hline Variety & $\begin{array}{l}\text { Density } \\
\text { (pl./ ha) }\end{array}$ & Ridge shape & $\begin{array}{c}\text { Total number of } \\
\text { tubers/ nest }\end{array}$ & $\%$ & Diff. & Signific $_{2}$ & $\begin{array}{c}\text { Duncan's } \\
\text { Test }\end{array}$ \\
\hline \multirow{6}{*}{ GARED } & \multirow{2}{*}{40.000} & Simple t. & 6,12 & 100,0 & 0 & Mt. & $E$ \\
\hline & & Double t. & 6,40 & 104,5 & 0,28 & - & $E$ \\
\hline & \multirow{2}{*}{60.000} & Simple t. & 5,35 & 100 & 0 & Mt. & $\mathrm{D}$ \\
\hline & & Double t. & 5,11 & 95,5 & $-0,24$ & - & $\mathrm{D}$ \\
\hline & \multirow{2}{*}{80.000} & Simple t. & 4,65 & 100 & 0,00 & Mt. & $\mathrm{D}$ \\
\hline & & Double t. & 4,97 & 106,8 & 0,32 & - & $\mathrm{D}$ \\
\hline \multirow{6}{*}{$\begin{array}{l}\text { BELLA } \\
\text { ROSA }\end{array}$} & \multirow{2}{*}{40.000} & Simple t. & 3,98 & 100 & 0 & Mt. & $\mathrm{C}$ \\
\hline & & Double t. & 3,67 & 92,3 & $-0,31$ & - & $\mathrm{C}$ \\
\hline & \multirow{2}{*}{60.000} & Simple t. & 2,87 & 100 & 0 & Mt. & $\mathrm{AB}$ \\
\hline & & Double t. & 3,37 & 117,5 & 0,50 & - & $\mathrm{BC}$ \\
\hline & \multirow{2}{*}{80.000} & Simple t. & 2,49 & 100 & 0 & Mt. & $\mathrm{A}$ \\
\hline & & Double t. & 2,56 & 103,1 & 0,08 & - & A \\
\hline \multicolumn{2}{|c|}{ DL (p 5\%) } & & 0,66 & & & & \\
\hline \multirow{2}{*}{\multicolumn{2}{|c|}{$\begin{array}{l}\text { DL (p 1\%) } \\
\text { DL (p 0,1\%) }\end{array}$}} & & 0,91 & & & & \\
\hline & & & 1,23 & & & & \\
\hline
\end{tabular}

Considering the interaction between variety, ridge shape and planting density upon the total number of tubers per plant no significant differences occurred among the variants. (table 14)

\section{CONCLUSIONS}

The highest yield of tubers was detected in the double trapezoidal shaped ridges at a density of 80000 plants per hectare for both varieties. This variant proves to be the most promising for harvesting seed potato and it will surely be the 
optimum choice in the future when we will be ready in terms of mechanization for the double ridge potato harvesting.

With great inputs of fertilizers used in large double trapezoidal shaped ridges with corresponding densities (60000 plants per hectare in the case of potato crop used for consumption and 80000 plants per hectare for seed potato production) yields can be increased significantly in regions that favor the cultivation of potato.

The average weight of a tuber is significantly higher in simple trapezoidal (165.5 g) and double trapezoidal (164.5 g) ridges than the average weight of a tuber harvested from triangular shaped ridges (143.75 g).

Considering averages on planting densities and ridge shapes the Bella Rosa variety, characterized by few but larger tubers, produced a significantly higher yield than the Gared variety with smaller tubers. Similarly to the previous trial year, the highest yield in 2013 was obtained at a density of 60000 plants / ha (25619 kg / ha).

A significantly higher potato crop yield was harvested from double trapezoidal shaped ridges than from simple trapezoidal ones.

The type of cultivar has a significant influence on the number of tubers under $40 \mathrm{~mm}$ in the planting hole.

Considering the influence of variety, ridge shapes and planting densities upon the number of tubers under $40 \mathrm{~mm}$ a significantly higher number of small tubers was discovered in the case of the Bella Rosa variety among the densities of
60000 plants per hectare and 80000 plants per hectare in double trapezoidal ridges as opposed to the number of small tubers harvested from simple trapezoidal ridges with the same planting densities.

At the same time taking into account the influence of variety, ridge shapes and planting densities upon the number of tubers over $40 \mathrm{~mm}$ per plant significant difference occurred in the case of the Gared variety planted at a density of 40000 plants per hectare in double trapezoidal shaped ridges, where a significantly higher number of large tubers was discovered in contrast with the simple trapezoidal shaped ones.

Considering the same interaction between variety, ridge shape and planting density influencing the total number of tubers per plant no significant differences among the variants were noted.

\section{REFERENCES}

1. Blaga Gh., F. Filipov, S. Udrescu, I. Rusu, D. Vasile, 2005, Pedologie, Ed. AcademicPres, p. 21, 22

2. Ianoși S., 1992, Importanța bilonului în cultura cartofului, Cartoful în România, Institutul de Cercetare și Producție a Cartofului Brașov, Vol. II, nr. 1, p. 18

3. Morar G., 2008, Fitotehnie, cap. VII., în volumul MUNTEAN L. S., S. CERNEA, M. M. Duda, G. Morar, D. I. Vârban, S. Muntean, 2008, Fitotehnie, Ed. AcademicPres, Cluj-Napoca, p. $454-460$

4. O.S.P.A. Brașov - Descrierea solurilor de la S.C.D.C. Târgu Secuiesc

5. *** Date meteorologice - Stația Meteorologică Târgu Secuiesc 